\title{
Pump Bottle
}

National Cancer Institute

\section{Source}

National Cancer Institute. Pump Bottle. NCI Thesaurus. Code C43174.

A bottle that is fitted with a pumping mechanism for the administration of drug product. 